\title{
Failure Mechanism Analysis and Support Design for Deep Composite Soft Rock Roadway: A Case Study of the Yangcheng Coal Mine in China
}

\author{
Bangyou Jiang, ${ }^{1}$ Lianguo Wang, ${ }^{1}$ Yinlong Lu, ${ }^{1}$ Shitan Gu, ${ }^{2}$ and Xiaokang Sun ${ }^{1}$ \\ ${ }^{1}$ State Key Laboratory for Geomechanics and Deep Underground Engineering, China University of Mining and Technology, \\ Xuzhou 221116, China \\ ${ }^{2}$ College of Mining and Safety Engineering, Shandong University of Science and Technology, Qingdao 266590, China
}

Correspondence should be addressed to Lianguo Wang; lgwang@cumt.edu.cn

Received 7 April 2015; Revised 29 May 2015; Accepted 3 June 2015

Academic Editor: Alicia Gonzalez-Buelga

Copyright @ 2015 Bangyou Jiang et al. This is an open access article distributed under the Creative Commons Attribution License, which permits unrestricted use, distribution, and reproduction in any medium, provided the original work is properly cited.

\begin{abstract}
This paper presented a case study of the failure mechanisms and support design for deep composite soft rock roadway in the Yangcheng Coal Mine of China. Many experiments and field tests were performed to reveal the failure mechanisms of the roadway. It was found that the surrounding rock of the roadway was HJS complex soft rock that was characterized by poor rock quality, widespread development of joint fissures, and an unstable creep property. The major horizontal stress, which was almost perpendicular to the roadway, was 1.59 times larger than the vertical stress. The weak surrounding rock and high tectonic stress were the main internal causes of roadway instabilities, and the inadequate support was the external cause. Based on the failure mechanism, a new support design was proposed that consisted of bolting, cable, metal mesh, shotcrete, and grouting. A field experiment using the new design was performed in a roadway section approximately $100 \mathrm{~m}$ long. Detailed deformation monitoring was conducted in the experimental roadway sections and sections of the previous roadway. The monitoring results showed that deformations of the roadway with the new support design were reduced by $85-90 \%$ compared with those of the old design. This successful case provides an important reference for similar soft rock roadway projects.
\end{abstract}

\section{Introduction}

Support for a soft rock roadway, especially for deep highstressed composite soft rock roadways, is a worldwide problem [1]. Composite soft rock is characterized by a brokenrock structure, low rock strength, intense water swelling, and rheological response $[2,3]$. In a complicated geomechanical environment (i.e., high in-situ stress, high ground temperature, high osmotic pressure, and strong mining disturbance), many roadways in deep coal mines with weak surrounding rocks experience severe deformations and failure, which not only reduces the functionality of the roadway but also endangers the safety of the mine personnel.

Recently, numerous studies have been performed on the failure mechanisms of deep soft rock roadways. He et al. performed an experiment and field investigation of the roadway of a loaded-car line that was seriously destroyed in the Xing'an Coal Mine, China, and found that the large buried depth and strong tectonic stress caused its failure [4]. Deep soft rocks are often cut by various weak planes (e.g., joint and bedding) [5]. Under high in-situ stresses, a shear slip will appear along these weak planes, which could loosen the structure of the surrounding rock and eventually caused an unstable failure of the roadway [6-8]. Seedsman and Yuan discussed the failure mechanisms of deep soft rock roadways $[9,10]$. Their studies showed that low rock strength and broken-rock structure lead to huge plastic deformations and finally failure. Wu et al. obtained the same conclusion [11]. In addition, Huang et al. presented the idea that, in a highstress environment, the soft rock had a strong rheological response and the rheological zone persistently developed toward the interior of the rock surrounding the roadway, 
which lead to instability [12]. However, different deep soft rock roadways have different failure mechanisms because of the complicated, changing engineering geological conditions. Based on a survey of a large number of documents, Shen concluded that various roadway failure mechanisms could be classified into six types: beam failure, joint controlled rock falls, roof sag, guttering and shear failure, skin failure, and rib failure [1]. This classification method has great value for applications and instructions. In general, a complicated geomechanical environment and weak mechanical properties of the surrounding rock are the original external and internal causes, respectively, of a deep soft rock roadway failure.

Research on the failure mechanisms of a roadway is a prerequisite of realizing the ultimate goal of a reasonable support design. Currently, bolt, anchor cable, grouting, yieldable steel sets, and combined supporting systems are widely employed in soft rock roadways in deep coal mines, but the most optimal supporting system is arguable. Bolting and bolting combined with metal net and shotcrete are extensively used in many countries such as the United States of America and Australia, whereas, in Germany, Poland, and other European countries, U-shaped steel sets are commonly used as the main support methods [13]. Because of the reasonable cross section shape and high strength, yieldable U-shaped steel supports are always used to maintain the stability of roadways in loose and broken-rock strata [14]. However, the high cost and complex process of installing these supports are the main disadvantages and fatal flaws of this support type. Recently, the yielding bolts support has become very popular. This method works by adding a yielding tube to the bolts [15]. Although this yielding support can adapt well to the deformation and pressure of a soft rock roadway, its strength and yielding capacity are limited. The yielding bolts support is seldom used in a large deformation broken soft rock roadway [16]. Wang et al. proposed a combined bolt and grouting support to control large deformations of a soft rock roadway and achieved good control of the deformations [17]. A new and effective support technology, the bolt-grouting support, has developed rapidly and has been widely employed in soft rock roadways and tunnel engineering [18-20]. Moreover, there are many other support technologies for soft rock, such as the concrete-filled steel tubular stent [21], constant resistance and large deformation bolts [22], and other combined support technologies [23-25]. However, these support technologies are unable to restrain the loose and broken rock surrounding a deep high-stress complicated soft rock roadway.

So, the failure mechanisms and support technologies of a soft rock roadway under complicated conditions have been the focus of research in mining engineering and other related fields. This paper reports a case study of the failure mechanisms and support design for a deep composite soft rock roadway in the Yangcheng Coal Mine in Shandong Province, China. In this paper, a large number of experiments and field tests were performed, and a mechanical model was developed. Furthermore, based on the failure mechanism and characteristic of the roadway, a new optimal support was proposed and more reasonable parameters were designed. The research results provide a significant reference for support design for similar roadway engineering projects.

\begin{tabular}{|c|c|c|c|}
\hline $\begin{array}{l}\text { Lithological } \\
\text { geological } \\
\text { column }\end{array}$ & $\begin{array}{c}\text { Thickness } \\
(\mathrm{m})\end{array}$ & Lithology & Lithology description \\
\hline & 10.51 & $\begin{array}{c}\text { Medium-grained } \\
\text { sandstone }\end{array}$ & $\begin{array}{c}\text { Shale cementation, existing } \\
\text { carbonaceous texture, bedding } \\
\text { development }\end{array}$ \\
\hline \\
\hdashline
\end{tabular}

FIGURE 1: Strata histogram of 3\# coal seam roof and floor.

\section{Geology and Engineering Background}

Located in the Jibei diggings in Shandong Province, the Yangcheng Coal Mine covers a mining area of $46 \mathrm{~km}^{2}$ (2.2 $6.7 \mathrm{~km}$ wide from east to west and $10.5 \mathrm{~km}$ long from north to south) with 153 million tons of recoverable reserves and an estimated production capacity of 2.4 million t/a. The -650 main roadway in the south wing was the horizontal development roadway that was responsible for ventilation and transportation to mining areas in the south wing for the next 12 years of production. Obviously, this roadway was very important to the whole coal mine. Due to faults, the roadway crossed over No. 3 coal seam and other weak strata on the roof and floor (Figure 1), which extremely reduced the strength and integrity of the surrounding rock.

The buried depth of the main roadway was approximately $700 \mathrm{~m}$. The cross section was a semicircle arch with straight walls. The walls were $1.8 \mathrm{~m}$ high, the arch was $2.4 \mathrm{~m}$ high, and the net width of the roadway was $4.8 \mathrm{~m}$. Primarily, bolts combined with anchor cables and metal mesh were used as the permanent support to control the surrounding rock. Three months after excavation, the roadway is seriously distorted, and the cross section area of some sections shrank by more than $80 \%$ (Figure 2). Subsequently, the damaged roadway had been repaired and reinforced. Based on the original support, seven grouting bolts with a diameter of $26 \mathrm{~mm}$ and a length of $2.5 \mathrm{~m}$ were evenly installed in the whole cross section at an interval of $2400 \mathrm{~mm}$ along the roadway axis. U-shaped steel sheds with a width of $4800 \mathrm{~mm}$ and a height of $4765 \mathrm{~mm}$ were placed at an interval of $1200 \mathrm{~mm}$. Furthermore, an inverted arch that matched the U-shaped steel sheds was used, and concrete was poured to $525 \mathrm{~mm}$ thickness. The support design is presented in Figure 3. However, the main roadway still suffered large deformations (Figure 4). Repeated repairs and reinforcements lead to the vicious circle of "excavationrepair-failure." Therefore, it is urgent to thoroughly study the failure mechanisms and optimize a support design. 


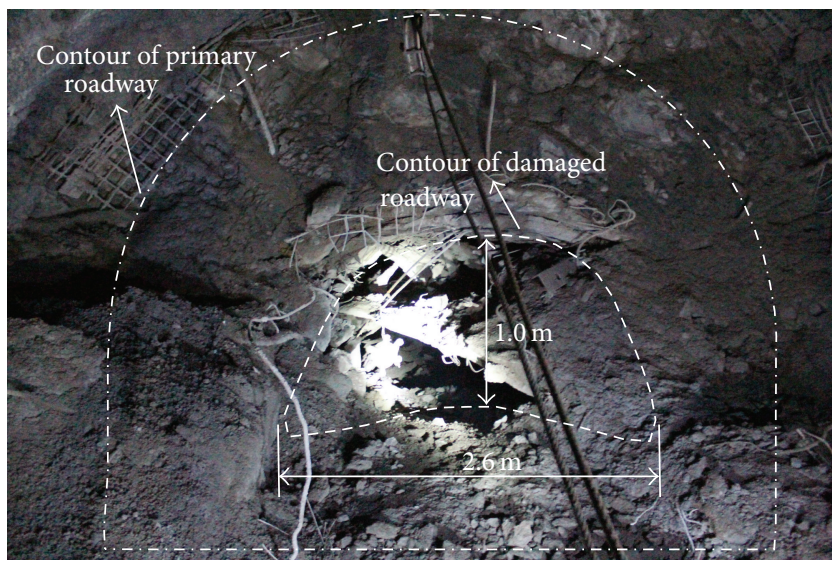

FIGURE 2: Large deformation of the roadway.

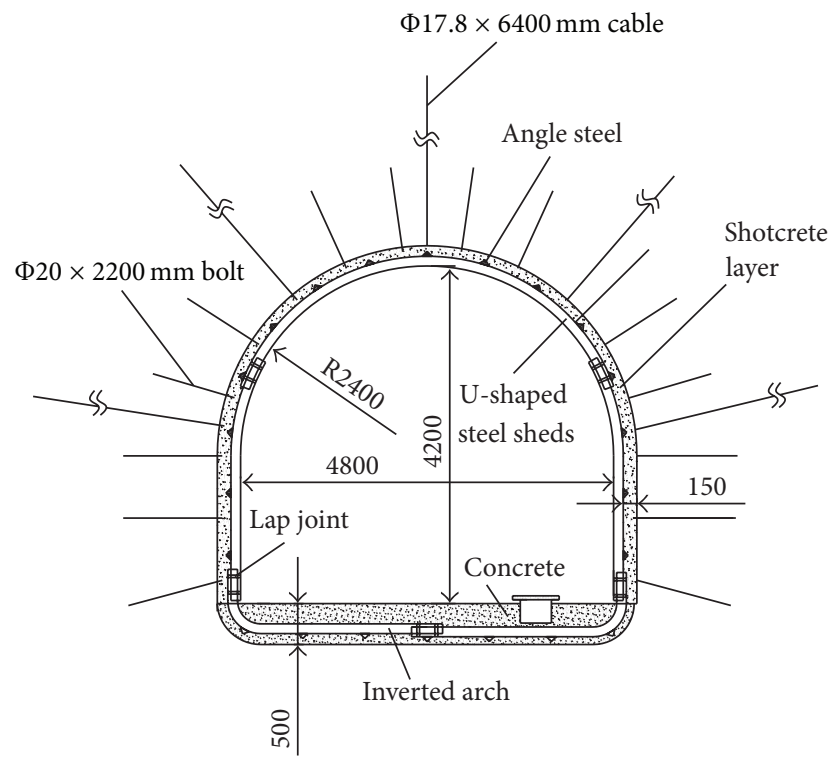

FIGURE 3: The old supporting design of the roadway.

\section{Experiments and Field Tests}

3.1. Physical and Mechanical Properties. The rock quality designation (RQD) is an index that provides a quantitative judgment of the rock mass quality, which can be obtained from drill cores [26, 27]. Core drilling was performed in four representative locations (\#1, \#2, \#3, and \#4) in the main roadway, as shown in Figure 5. The RQD of the four locations were $21.9 \%, 21.4 \%, 43.1 \%$, and $25.8 \%$, respectively. The descriptive statistics of the RQD samples are presented in Table 1. From the statistics in Table 1, the rock quality at locations \#1 and \#2 was very poor (Classification V). Similarly, the rock quality at location \#3 and \#4 was poor (Classification VI). This indicated that the integrity of the rock surrounding the main roadway was low, which allowed wide development of joint fissures.

Rock samples were divided into siltstone, fine sandstone, medium-grained sandstone, and mudstone according to
TABLE 1: Classification criterion of rock quality by the RQD [26, 27].

\begin{tabular}{lcc}
\hline RQD $(\%)$ & Classification & Rock quality \\
\hline$<25$ & V & Very poor \\
$25-50$ & IV & Poor \\
$50-75$ & III & Fine \\
$75-90$ & II & Good \\
$90-100$ & I & Excellent \\
\hline
\end{tabular}

their lithological characteristics. Conventional physical and mechanical tests were conducted on rock samples using a MTS 815.02 rock servo-hydraulic machine. Test results are listed in Table 2. The (4) and (5) mudstone samples are very weak. They are typical soft rock samples due to their low uniaxial compressive strengths (24.13 $\mathrm{MPa}$ and $23.05 \mathrm{MPa}$ ) and tensile strengths (1.63 MPa and $2.22 \mathrm{MPa})$. The (1) -(3) sandstone samples have high strength with uniaxial compressive strengths greater than $30 \mathrm{MPa}$. The uniaxial compressive strength of the (1) siltstone sample is $47.46 \mathrm{MPa}$. However, because of the wide development of joint fissures in the surrounding rock, the whole engineering rock mass is significantly distorted under the action of engineering forces; therefore, this sample has the characteristics of a jointed soft rock.

To study the softening characteristics of water in the surrounding rock, a saturated water content test was conducted on the surrounding rock sample. The uniaxial compressive strengths of the water-saturated samples are presented in Table 2. The uniaxial compressive strength of water-saturated samples decreases significantly. The softening coefficient of the (5) mudstone in the water-saturated condition is 0.28 . The (4) mudstone disintegrated in water (Figure 6). Rock samples contain expansible hydrophilic clay minerals that quickly absorb water molecules when the samples are soaking in water, which will destroy the microstructure, decrease the strength, and even disintegrate the rock samples.

In addition, uniaxial creep tests of the rock samples were performed using a multistep incremental loading. The loading rate of each stage was $40 \mathrm{~N} / \mathrm{s}$ and the duration of each stage was approximately $24 \mathrm{~h}$. Some results of the creep test are shown in Figure 7. The creep tests demonstrated that the surrounding rock in the main roadway has an unstable creep property and the critical strength of the unstable creep deformation of different rock samples ranges within 12 20 MPa. Based on the comprehensive analysis, the surrounding rock in the main roadway of the Yangcheng Coal Mine is an HJS complex soft rock with combined characteristics of a jointed soft rock, expansible soft rock, and high-stress soft rock [2].

\subsection{In Situ Stresses}

3.2.1. Gravity Stress Field. The overall buried depth of the main roadway is approximately $700 \mathrm{~m}$. The mean volumeweight of the overlying rock is approximately $25 \mathrm{KN} / \mathrm{m}^{3}$, so the gravity stress is $17.5 \mathrm{MPa}$, higher than the strength of 
TABLE 2: Physical and mechanical parameters of surrounding rocks.

\begin{tabular}{|c|c|c|c|c|c|c|c|c|}
\hline \multirow[b]{2}{*}{$\begin{array}{l}\text { Serial } \\
\text { number }\end{array}$} & \multirow[b]{2}{*}{ Lithology } & \multicolumn{5}{|c|}{ Natural specimens } & \multicolumn{2}{|c|}{ Saturated specimens } \\
\hline & & $\begin{array}{c}\text { Bulk } \\
\text { density } \\
\left(\mathrm{KN} \cdot \mathrm{m}^{3}\right)\end{array}$ & $\begin{array}{l}\text { Uniaxial } \\
\text { compressive } \\
\text { strength } \\
(\mathrm{MPa})\end{array}$ & $\begin{array}{c}\text { Tensile } \\
\text { strength } \\
(\mathrm{MPa})\end{array}$ & $\begin{array}{c}\text { Poisson's } \\
\text { ratio }\end{array}$ & $\begin{array}{c}\text { Elastic } \\
\text { modulus } \\
(\mathrm{GPa})\end{array}$ & $\begin{array}{l}\text { Uniaxial } \\
\text { compressive } \\
\text { strength } \\
(\mathrm{MPa})\end{array}$ & $\begin{array}{l}\text { Softening } \\
\text { coefficient }\end{array}$ \\
\hline (1) & Siltstone & 25.70 & 47.46 & 5.82 & 0.25 & 5.89 & 22.78 & 0.48 \\
\hline (2) & Fine sandstone & 25.16 & 31.85 & 3.76 & 0.13 & 5.23 & 17.20 & 0.54 \\
\hline (3) & $\begin{array}{l}\text { Medium-grained } \\
\text { sandstone }\end{array}$ & 24.61 & 30.14 & 4.49 & 0.18 & 5.23 & 22.00 & 0.73 \\
\hline (4) & Mudstone & 24.65 & 24.13 & 1.63 & 0.11 & 3.10 & - & - \\
\hline (5) & Mudstone & 25.75 & 23.05 & 2.22 & 0.10 & 4.30 & 6.45 & 0.28 \\
\hline
\end{tabular}

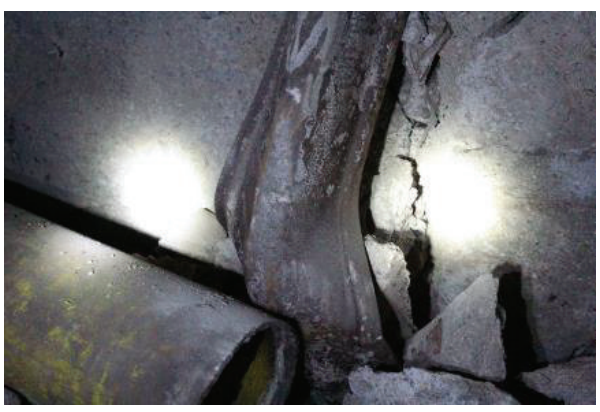

(a) Shed leg twisted

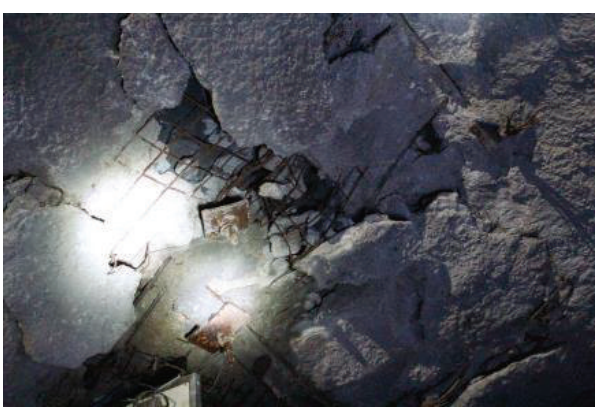

(c) Roof fractured

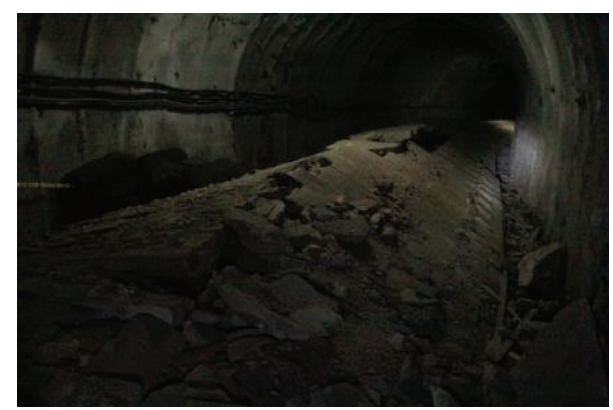

(b) Floor heaved seriously

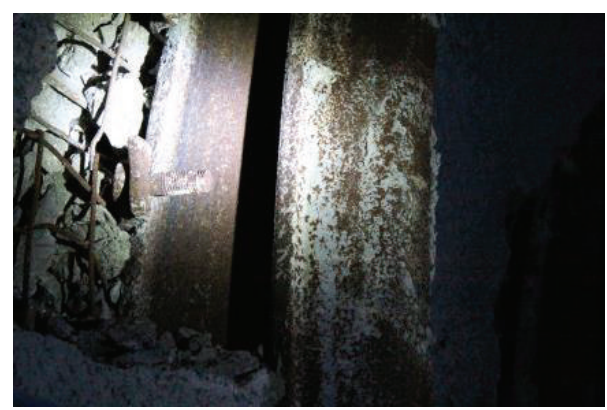

(d) Connection failure

FIGURE 4: Deformation and failure of the roadway after repairing.

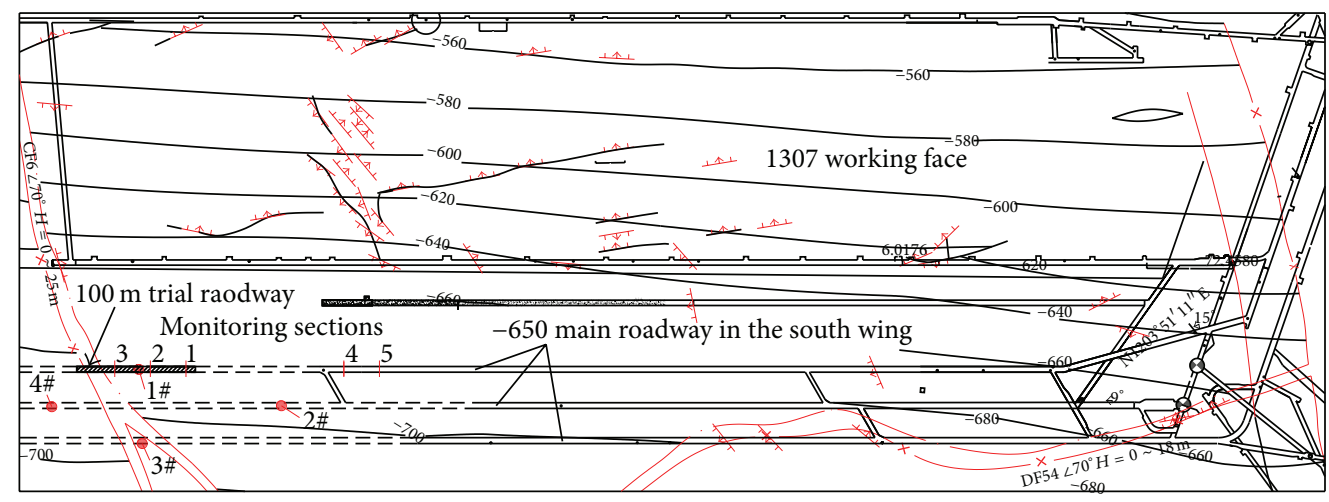

Figure 5: The locations of boreholes 1\# 4\#. 


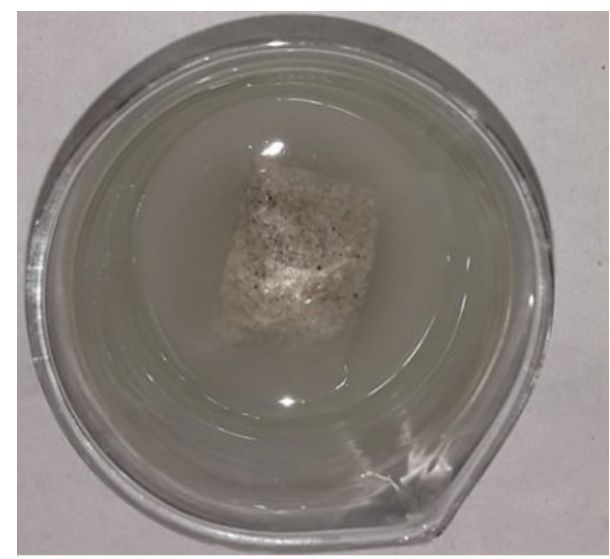

$4 \mathrm{~h}$

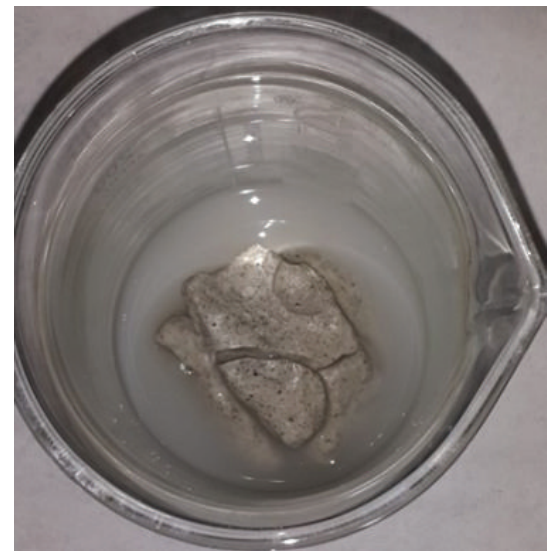

$24 \mathrm{~h}$

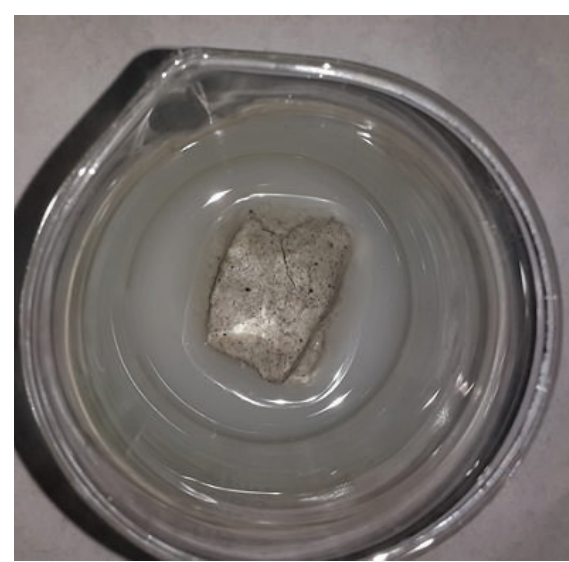

$12 \mathrm{~h}$

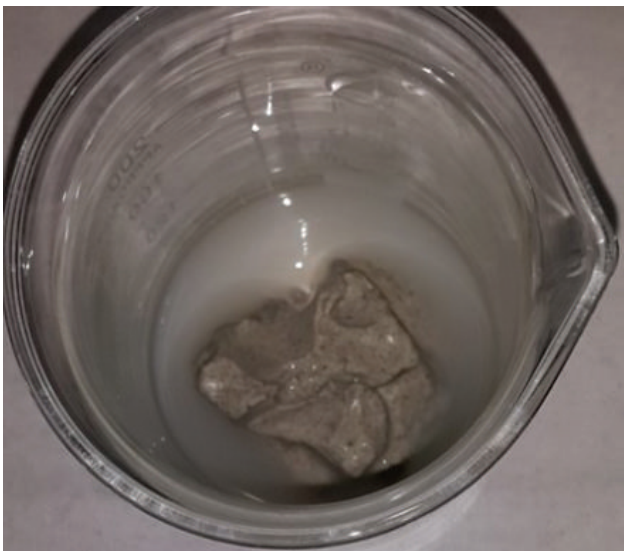

$2 \mathrm{~d}$

FIGURE 6: Water-induced weakening process of mudstone.

the surrounding rock. The critical strength of the unstable creep deformation of different surrounding rock strata is 12 $20 \mathrm{MPa}$, which is easily exceeded by the surrounding rock stress because of roadway excavation. This explains why the surrounding rock has large nonlinear flow deformations after roadway excavation.

3.2.2. Tectonic Stress Field. Based on the tectonic stress test results for the Yangcheng Coal Mine [28], the major principal stress in the in situ stress field is the horizontal stress. The azimuth angle of the maximum principal horizontal stress is $112.3^{\circ}$. The maximum principal horizontal stress is $27.81 \mathrm{MPa}$ or 1.59 times greater than the vertical stress and 1.92 times greater than the minimum principal horizontal stress $(14.47 \mathrm{MPa})$. The angle between the axis of the main roadway and maximum principal horizontal stress is $87.7^{\circ}$. The influence of the horizontal stress on the main roadway during excavation can lead to severe failure of the roadway.

3.3. Broken-Rock Zone and Failure Characteristics. The broken-rock zone and failure characteristics were detected by a borehole TV in several typical sections of the main soft rock roadway (Figure 8 ). The field borehole TV detection discovered that the rock surrounding the main roadway can be divided into intact, crack, and fracture zones according to the degree of failure [29], as shown in Figure 9. An intact zone is defined as a region in which no fissures are observed along a continuous distance of $30 \mathrm{~cm}$ of the borehole. A crack zone is defined as a region that contains 1-2 sets of fissures along a continuous distance of $30 \mathrm{~cm}$ of the borehole. A fracture zone is a region that contains three or more fissures or evident fracture along a continuous distance of $30 \mathrm{~cm}$ of the borehole.

The surrounding rock failure of the main air return roadway was analyzed based on these definitions of zones. Generally speaking, the surrounding rock is seriously distorted, with a large broken-rock zone (approximately $2 \sim 3 \mathrm{~m}$ and even reaching $5 \mathrm{~m}$ in some places) and discontinuous asymmetrical failure. Many crack zones and fracture zones are observed within a $3 \mathrm{~m}$ range of the surrounding rock. When the borehole depth exceeds $3 \mathrm{~m}$, the crack zone and intact zone occur alternately. As the borehole goes deeper, the length of the intact zone gradually increases. The depth of the surrounding rock failure is very large, and the crack zone still can be detected at a depth of 8-10 $\mathrm{m}$. 


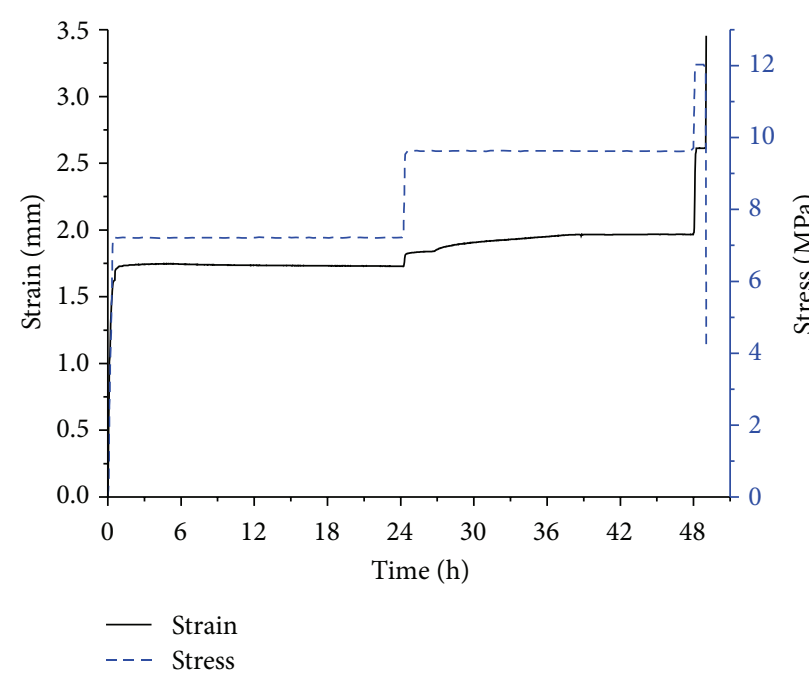

(a) Rock sample of mudstone

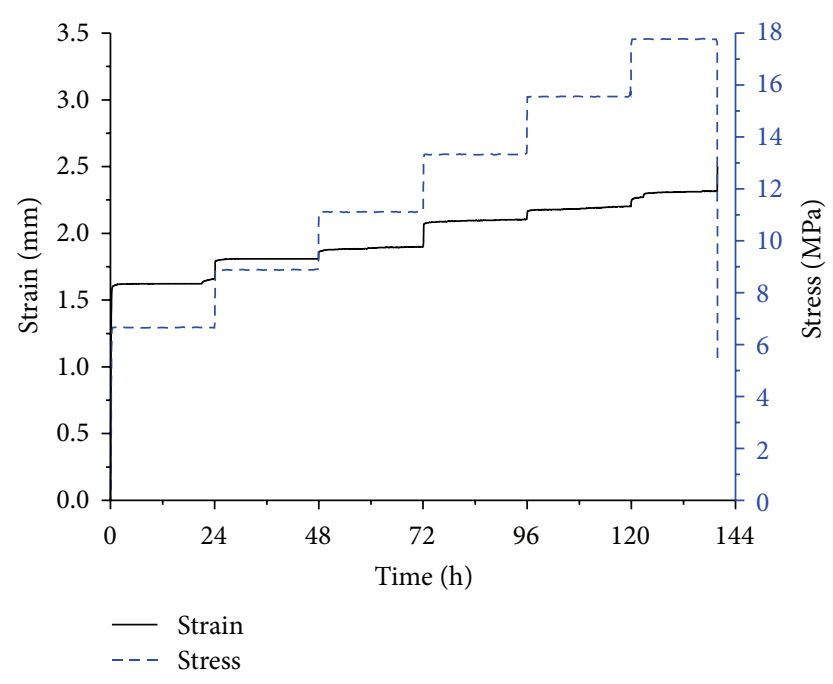

(b) Rock sample of medium-grained sandstone

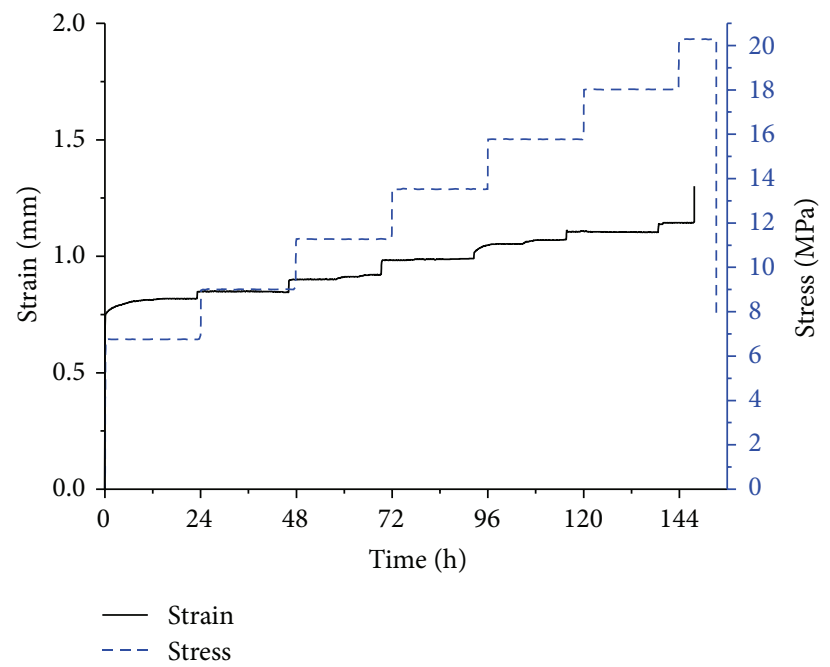

(c) Rock sample of fine sandstone

FIGURE 7: Uniaxial creep strain and creep stress curves.

\section{Failure Mechanism of the Main Soft Rock Roadway}

Experimental and field tests showed that the internal causes for the instability of the roadway were the weak surrounding rock and high tectonic stress. The unreasonable support design was the external cause.

Low strength and wide development of joint fissures of the surrounding rock significantly decrease the bearing capacity of the surrounding rock. The horizontal stress (1.59 times greater than the vertical stress), which is the major principal stress in the in situ stress field, is almost perpendicular to the roadway direction. The high horizontal stress caused a major concentration stress in the roof and floor of the roadway. Deformation and instability first occurred in the roof and floor.

After failure of the roadway roof and floor, the rock masses against the two roadway ribs had large stress concentrations in a biaxial stress state. The concentrated stress causes the abundant primary joint fissures to expand and interconnect with each other to form an unstable surrounding rock structure with a fracture zone and crack zone occurring alternately. Because the surrounding rock in the fracture zone loses bearing capacity completely, the abutment pressure of the rock surrounding the roadway migrates to the crack zone and deeper intact zone, which will turn the crack zone into a fracture zone and the intact zone into a crack zone until the surrounding rock stabilizes.

The borehole TV showed that the broken-rock zone of the roadway was approximately $2-3 \mathrm{~m}$, which exceeded the effective anchorage length of the bolts. The maximum failure depth of the crack zone in the roadway extended 8-10 m, which was wider than the length of the cables. So the bolts and cables were in fact useless, and the U-shaped steel sheds were unable to support the deformations of the large quantity of broken surrounding rock. 


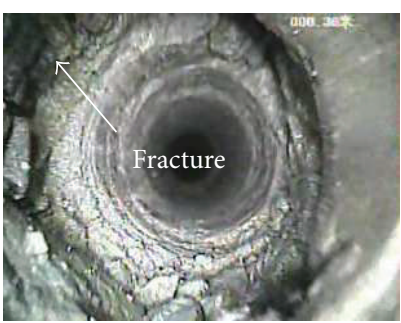

Fracture of $0.36 \mathrm{~m}$ deep

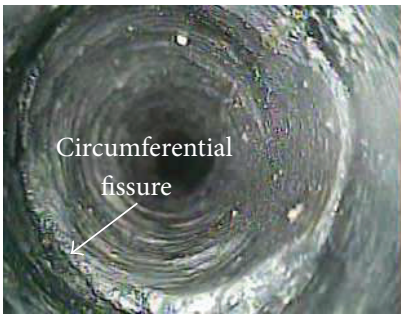

Fissure of $4.12 \mathrm{~m}$ deep

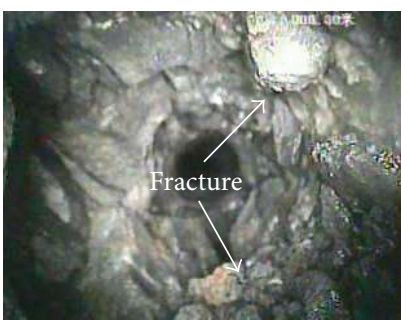

Fracture of $0.3 \mathrm{~m}$ deep

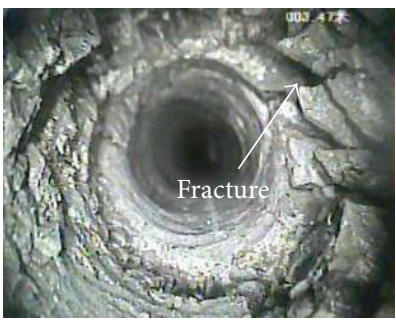

Fracture of $3.47 \mathrm{~m}$ deep

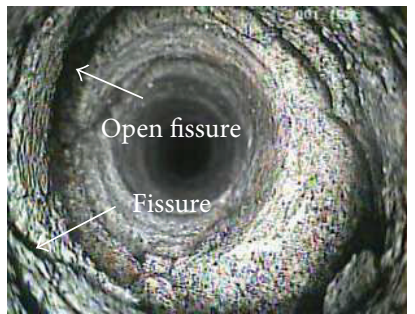

Fissures of $1.15 \mathrm{~m}$ deep

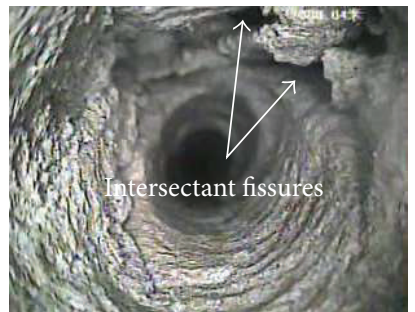

Fissures of $8.04 \mathrm{~m}$ deep

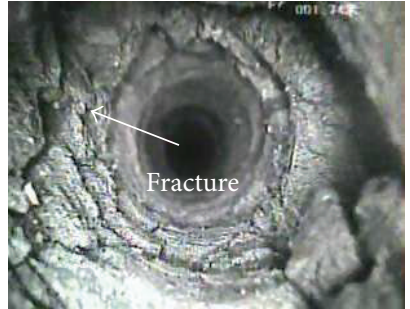

Fracture of $1.74 \mathrm{~m}$ deep

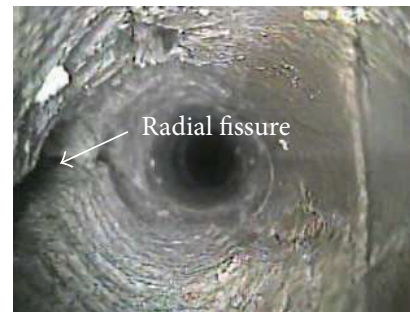

Fissure of $8.82 \mathrm{~m}$ deep

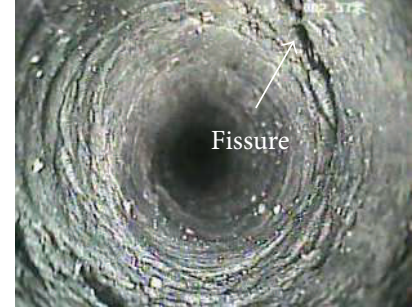

Fissure of $2.57 \mathrm{~m}$ deep

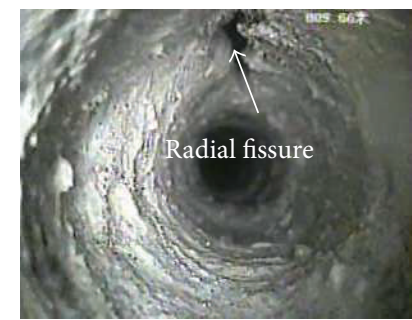

Fissure of $9.66 \mathrm{~m}$ deep

(a) Drilling in the roof strata

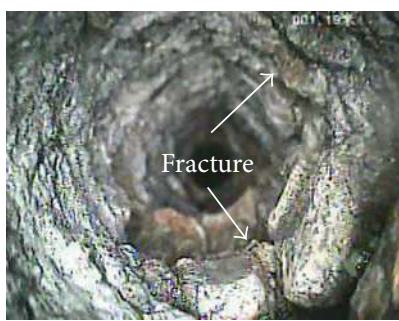

Fracture of $1.19 \mathrm{~m}$ deep

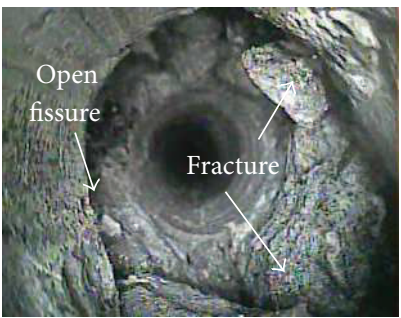

Fissure and fracture of $4.73 \mathrm{~m}$ deep

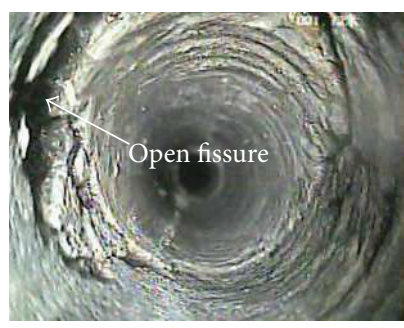

Open fissure of $1.73 \mathrm{~m}$ deep

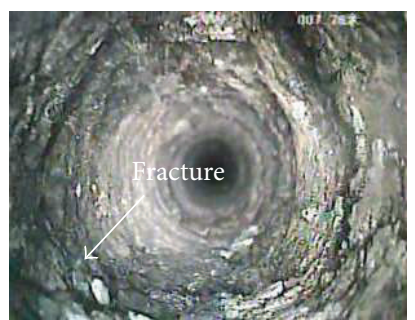

Fracture of $7.76 \mathrm{~m}$ deep

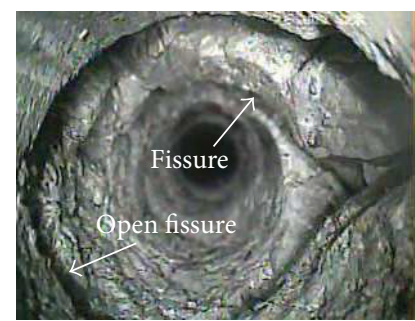

Fissures of $3.32 \mathrm{~m}$ deep

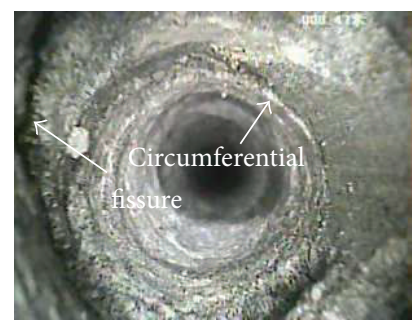

Fissure of $8.47 \mathrm{~m}$ deep

(b) Drilling in the ribs strata

FIGURE 8: Fracture patterns of surrounding rocks from borehole TV observation.

\section{Support Design}

Although the supporting capacity of the previous support was very high, the main roadway deformed seriously. The old support design is unscientific and lacking specificity. A new and better support design is needed to control the roadway deformations and instability. Based on the results of experiments and field tests, the new design should consider the following.

(1) Rapid support installation after excavation [1]: the surrounding rock of the deep high-stress roadway may deform immediately after roadway excavation because of the stress concentration. Therefore, installing the bolts and cables at an early stage is essential and can avoid premature yield failure of the surrounding rock and allow the support to work with the intact rock.

(2) Long cable: field tests showed that the depth of the surrounding rock failure was very large, and many cracks still can be detected $8 \mathrm{~m}$ deep or deeper. The cable length of the old support is $6.4 \mathrm{~m}$, which is much less than the depth of the surrounding rock failure, so it cannot control the stability of the surrounding rock. The new long cable should terminate inside the relatively intact rock. So the length of new long cables 


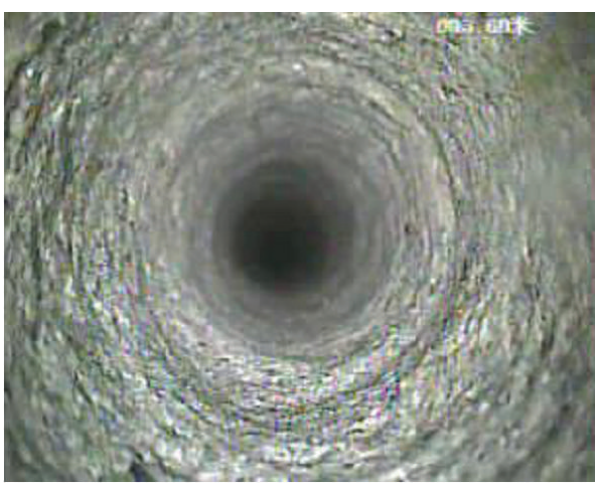

(a) Intact zone

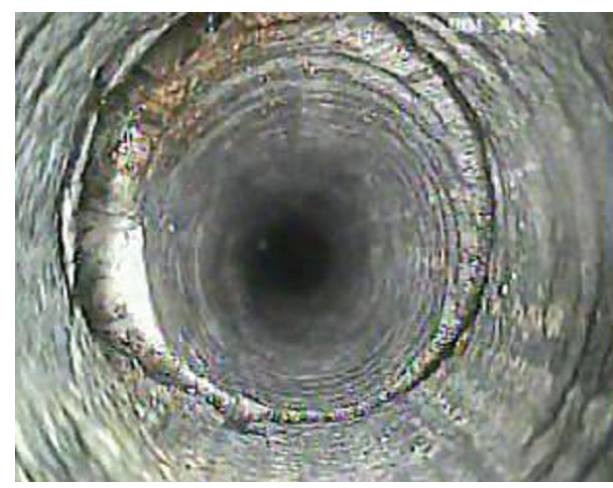

(b) Crack zone

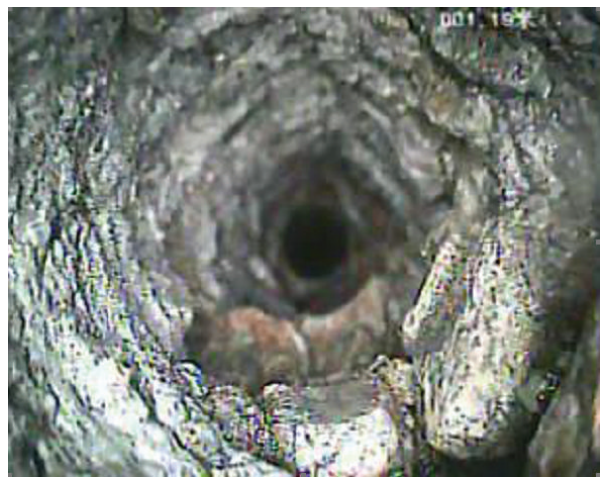

(c) Fracture zone

FIGURE 9: Three typical zones around the surrounding rock.

should be greater than the depth of the surrounding rock failure.

(3) Grouting reinforcement: field test results showed that the surrounding rock was weak because of wide development of joint fissures and a large brokenrock zone; these conditions were the main causes of the roadway instability. The best way to improve this is to use a grouting reinforcement support because this can rebuild loose and broken surrounding rock into a solid rock. Another benefit is that grouting can seal fissures of the surrounding rock and prevent infiltration of water and air, avoiding the softening effect of water and air on the rocks and increasing bearing capacity.

(4) High pretension: high pretension plays an important role in roadway support because it can significantly enhance the strength of the anchorage body.

Based on these considerations, a new support design was presented. The specific layout of the bolts, cables, and so forth is shown in Figure 10. The new support combines bolting, shotcreting with wire mesh, anchor cabling, and grouting. Moreover, a deep and superficial coupling grouting support is achieved with a grouting pipe and grouting cable, as seen in Figure 10. The grouting pipe rebuilds the broken surrounding rocks by forming an integral load-bearing ring, whereas the grouting cable seals the deep fracture and stabilizes the superficial load-bearing ring. The floor is supported by an overbreak and bolt-grouting backfill technology that can increase the integrity and bending resistance of the floor. Specific support parameters in the new support design are introduced as follows.

(1) Bolt parameters: there are twenty-five bolts in the roadway cross section, including eight bolts in the roof, twelve bolts in the ribs, and five bolts in the floor. The bolts have a diameter of $22 \mathrm{~mm}$ and a length of $2.5 \mathrm{~m}$. The spacing between the bolts in the roof and ribs along the roadway axis is $0.7 \mathrm{~m}$. The spacing between the bolts in the roof and ribs along the roadway radial is $0.7 \mathrm{~m}$. The spacing between the bolts in the floor is $0.9 \mathrm{~m}$. Metal meshes are applied before the anchor rod reinforcement. Fifty-millimeter thick shotcrete will be constructed (primary shotcrete) as soon as possible after the bolting support. The anchorage length of each bolt must be greater than $0.6 \mathrm{~m}$. All bolts should be pretensioned with a pretension load of $70 \mathrm{kN}$. The bolts are made of levorotary rebar steel with a tensile strength of $500 \mathrm{MPa}$.

(2) Metal mesh parameters: metal mesh is welded to steel bar that has a diameter of $6 \mathrm{~mm}$. The metal mesh has a length of $2.0 \mathrm{~m}$ and a width of $1.0 \mathrm{~m}$. The grid of the metal mesh has a length/width ratio of 0.1 . The metal mesh is installed to the whole roadway section, and two adjacent metal meshes are connected by iron wire. 


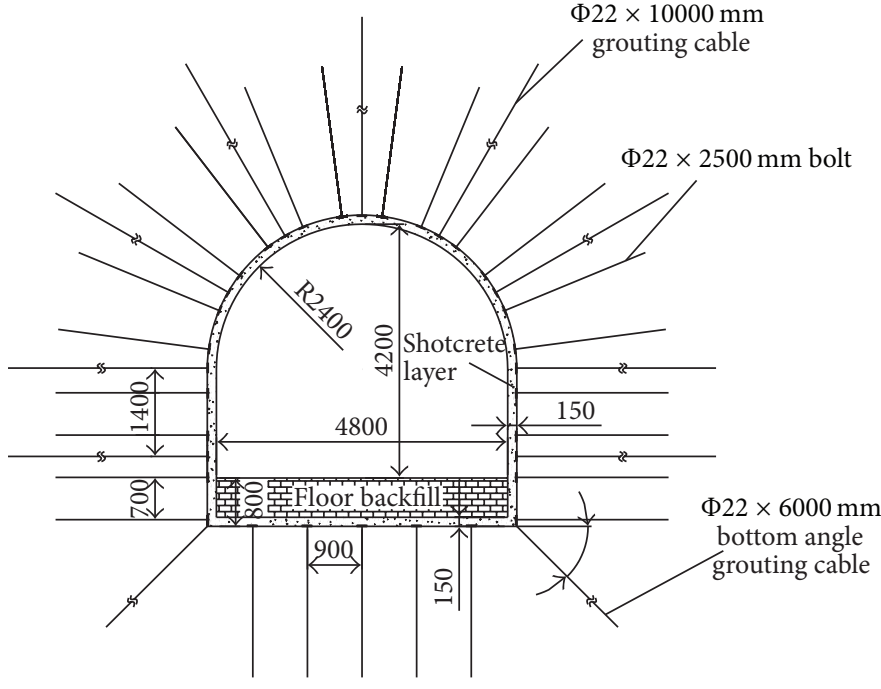

(a) Anchor robs and cables support design

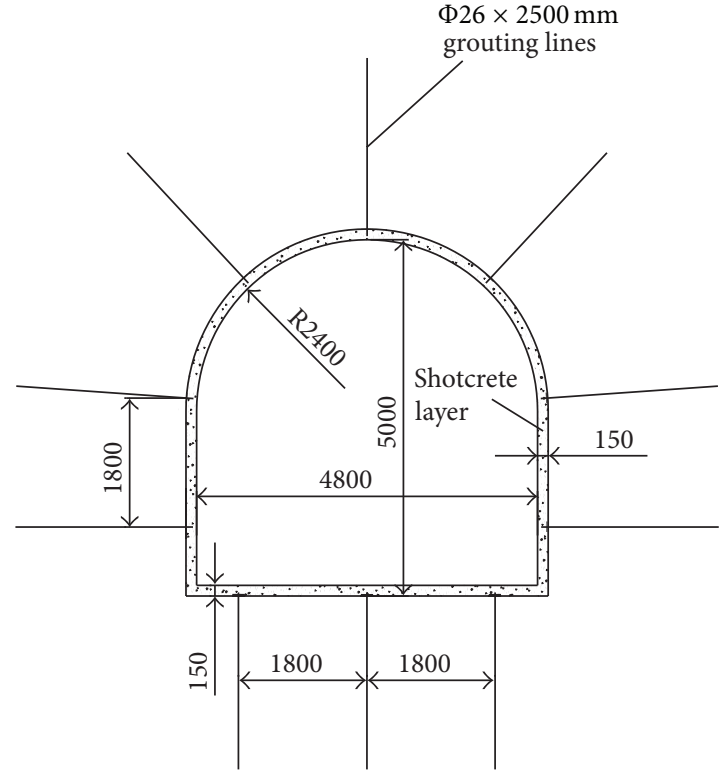

(b) Grouting lines support design

Figure 10: New supporting design of the roadway.

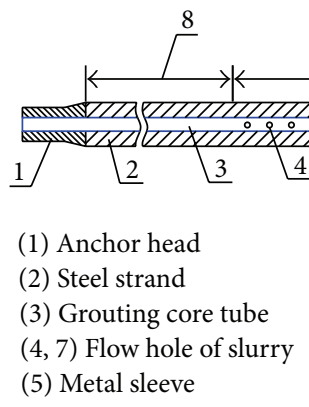

FIGURE 11: Structure of grouting cable.

(3) Grouting pipe parameters: there are ten grouting pipes in a roadway cross section including five in the roof, two in the ribs, and three in the floor. The grouting pipes have a diameter of $26 \mathrm{~mm}$ and a length of $2.5 \mathrm{~m}$. The intervals between the grouting pipes along the roadway axis and radial are both $1.8 \mathrm{~m}$. Grouting lines are paved immediately after the primary shotcrete support.

(4) Grouting cable parameters: based on the surrounding rock deformation characteristics of the roadway measured from experiments and field tests, a new grouting cable is designed, as seen in Figure 11. The new grouting cable has many advantages such as a small grouting resistance, large flow, high efficiency, and wide application range. Gradual grouting from the deep surrounding rock to the superficial surrounding rock can be achieved with high and low pressure grouting sections of the new grouting cable. There are eleven grouting cables in a roadway cross section including five in the roof, four in the ribs, and two in the bottom angle. The grouting cables have a diameter of $22 \mathrm{~mm}$ and a length of $10.0 \mathrm{~m}$ in the roof and ribs and $6.0 \mathrm{~m}$ in the bottom angle. The intervals between the grouting cables in the roof and ribs along the roadway and radial axes are both $1.4 \mathrm{~m}$. The spacing between the grouting cables in the bottom angle along the roadway axis is $1.4 \mathrm{~m}$. The anchorage length of each grouting cable must be larger than $1.5 \mathrm{~m}$. All grouting cables should be pretensioned with a pretension load of $200 \mathrm{kN}$. The grouting cables are made of steel strand with a tensile strength of $1860 \mathrm{MPa}$. Grouting cables are installed after the grouting pipes, and secondary shotcrete with the thickness of $100 \mathrm{~mm}$ is applied as soon as the grouting cable pavement is finished.

(5) Grout parameters: the grout is a single liquid prepared from Po42.5 ordinary silicate cement with a water/cement ratio of $1: 2$. The final grouting pressure of the grouting-anchor cable is $3 \sim 4 \mathrm{MPa}$ and the final grouting pressure of the grouting lines is $1.5 \sim 2 \mathrm{MPa}$ [17]. The grouting is implemented within 15 18 days after roadway excavation so the grouting is most effective [30].

(6) Concrete parameters: the strength of the sprayed concrete is C20 and the strength of the concrete for floor backfilling is C40, which includes an added waterproofing agent. Normal concrete easily breaks when the surrounding rock experiences a large deformation. Hence, steel fibers are added in the concrete to increase flexibility and deformability of the concrete layers. Furthermore, the metal meshes can also increase the tensile strength of the concrete layers. 


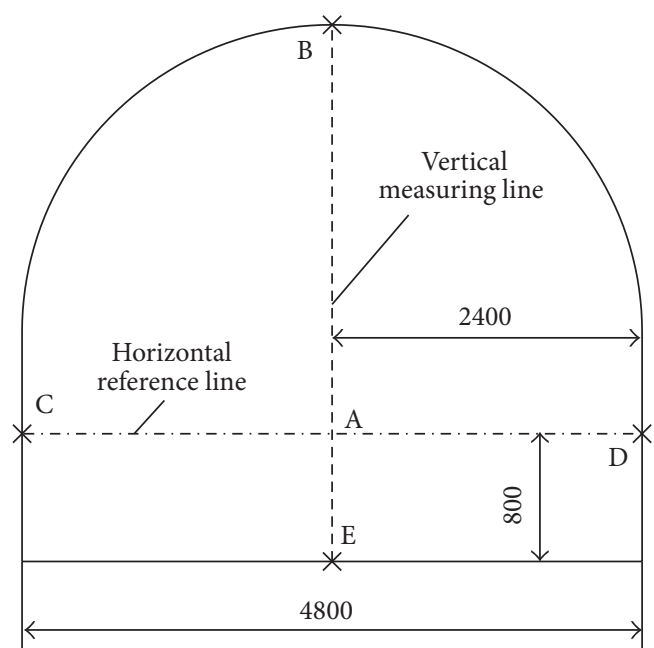

FIGURE 12: Monitoring sites for the deformation of the roadway.

Backfilling the extra excavation space of the floor with concrete is conducted last.

Compared to the old support design, the new support design can bond the support with the surrounding rock of the roadway and fully utilize the self-supporting capability of the surrounding rock.

\section{On-Site Experiments and Monitoring}

Field industrial experiments and monitoring were performed in the -650 main roadway in the south wing of the Yangcheng Coal Mine to test the effectiveness of the new support design and compare it with the old support design. One $100 \mathrm{~m}$ segment of roadway was chosen as a trial of the new support design, and the other roadways were supported with the old support design shown in Figure 3. The deformation of the roadway was measured by extensometers with $0.2 \mathrm{~mm}$ accuracy. A total of five roadway cross sections were monitored at an interval of $30 \mathrm{~m}$ between two sections. Monitoring sections 1,2 , and 3 were in the roadway with the new support design, and monitoring sections 4 and 5 were in the roadway with the old design. The locations of the monitoring sections are shown in Figure 5.

The measuring method of each cross section is shown in Figure 12. In Figure 12, B and E are two vertical data marks fixed in the roof and floor of the roadway, respectively, and $\mathrm{C}$ and $\mathrm{D}$ are two horizontal data marks fixed in the ribs. $\mathrm{CD}$ is the horizontal reference line, and $\mathrm{BE}$ is the vertical measuring line. $\mathrm{A}$ is the node of $\mathrm{CD}$ and $\mathrm{BE}$. A decreasing length of CD means shrinkage of the two ribs, a decreasing length of BA means settlement of the roof and a decreasing length of $\mathrm{AE}$ means heaving of the floor.

Monitoring of all five roadway cross sections started as soon as possible after all of the supports were installed. Monitoring for sections 1 to 3 lasted for 90 days. Deformation and the deformation rate were both very large in the roadway with the old support design; therefore, to ensure safety of the workers, sections 4 and 5 were monitored for only 70 days.
The monitoring results are shown in Figures 13, 14, 15, and 16. The monitoring results of sections 1 to 3 showed that there was an obvious increase in the deformation during the first 12 days after supporting the roadway. However, after approximately 12 days, the deformation rates started to decrease, and the deformations appeared to be stable after approximately 30 to 60 days. For the comparable sections 4 and 5 with the old support design, the deformation continued to increase over the whole monitoring period, and no obvious decline in the deformation rates was observed during the monitoring period.

After monitoring, the maximum monitored ribs convergence, roof settlement, and floor heave in the roadway with the new support design were $56 \mathrm{~mm}$ (section 3), $44 \mathrm{~mm}$ (section 1 ), and $44 \mathrm{~mm}$ (section 3 ), respectively. In sections 4 and 5 with the old support design, these results were $601 \mathrm{~mm}$ (section 4), $295.6 \mathrm{~mm}$ (section 4), and $517.2 \mathrm{~mm}$ (section 5), respectively. It is clear that the roadway deformation with the new support design is much smaller than that with the old design. A similar conclusion is drawn by comparing the deformation rates of the ribs convergence, roof settlement, and floor heave in the roadway with the new support design and the old design. The highest deformation rates of the two ribs, roof, and floor of the roadway with the new support design were $3 \mathrm{~mm} / \mathrm{d}, 4 \mathrm{~mm} / \mathrm{d}$, and $2.7 \mathrm{~mm} / \mathrm{d}$, respectively, compared to $17 \mathrm{~mm} / \mathrm{d}, 10 \mathrm{~mm} / \mathrm{d}$, and $14 \mathrm{~mm} / \mathrm{d}$ in the roadway with the old design.

In general, compared with the old support design, the new support design can reduce the roadway deformation by at least $85-90 \%$. During the monitoring period, the roadway roof, ribs, and floor with the new support design were intact and no obvious failure was visible. In contrast, the roadway with the old design experienced large deformations and severe failure. This indicates that the new support design can effectively control the deformation of the roadway and maintain stability of the roadway. The effectiveness of the new support design can be visually observed in Figure 17.

\section{Conclusions}

A case study of the failure mechanisms and support technology for deep composite soft rock roadways was performed on the Yangcheng Coal Mine in Shandong Province, China. The buried depth of the main roadway was approximately $700 \mathrm{~m}$, and the surrounding rock of the roadway was weak and broken. Bolts combined with cables, metal mesh, and even U-shaped steel sheds were used as permanent supports to control the surrounding rock. However, the main roadway still suffered large deformations and seriously unstable failures.

Both a field survey and an experimental study showed that the surrounding rock of the roadway was an HJS complex soft rock characterized by poor rock quality, wide development of joint fissures, and an unstable creep property. The broken-rock zone of the roadway surrounding rock was large and the maximum depth of the fissures exceeded $8 \mathrm{~m}$. The tectonic stress field test showed that the major horizontal stress was approximately 1.59 times greater than the vertical 


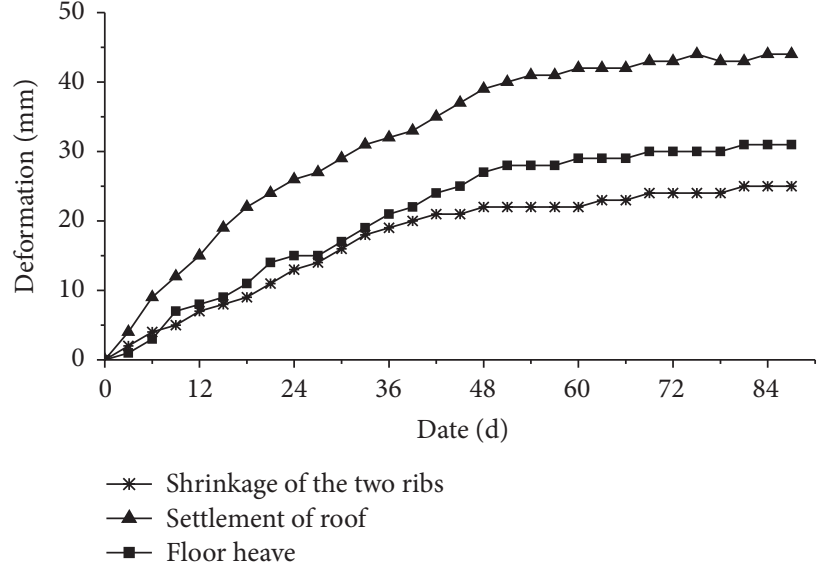

(a) Roadway cross section 1

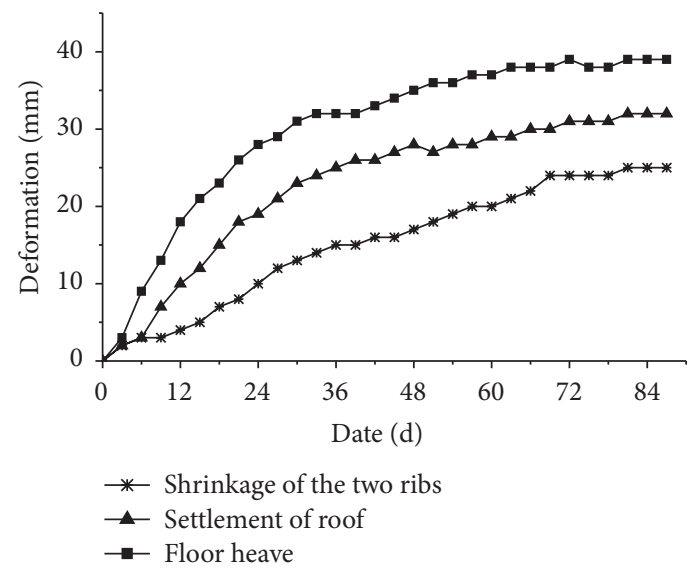

(b) Roadway cross section 2

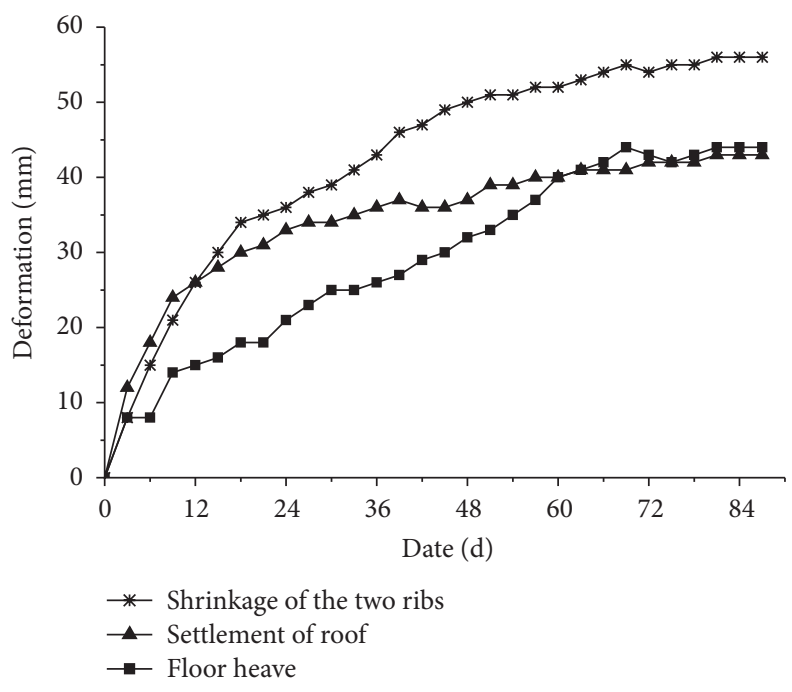

(c) Roadway cross section 3

Figure 13: The cumulative deformation of the roadway with the new support design.

stress. The angle between the axis of the main roadway and the major horizontal stress was $87.7^{\circ}$. The weak surrounding rock and high tectonic stress were the main internal causes of roadway instabilities, and the unreasonable support design was the external cause.

Based on the results of experiments, field tests, and extensive analysis, a new support design was proposed, which included a reasonable support arrangement, long cables, grouting reinforcement, high pretensioning of bolts and cables, and overbreak and bolt-grouting backfill for the floor support. Furthermore, a new grouting cable was invented specifically to control the roadway deformation and failure.

An on-site industrial experiment of the new support design was performed in a roadway section approximately $100 \mathrm{~m}$ long. The monitoring results confirmed that the new support design was much more effective than the old design. The new support design reduced the deformations of the roadway by at least $85-90 \%$ compared to that of the previous roadway. This case study indicated that a deep composite soft rock roadway similar to the -650 main roadway in the south wing of the Yangcheng Coal Mine could be steadily controlled with an elaborate field investigation, scientific analysis, and reasonable support design. The success of this case provides significant guidance for similar roadway construction engineering projects, which will be welcomed by other coal mines.

\section{Conflict of Interests}

The authors declare that there is no conflict of interests regarding the publication of this paper.

\section{Acknowledgments}

This work was supported by the National Basic Research Program of China (2014CB046905), the National Natural Science Foundation of China (51274191, 51404245, 51374140, and 


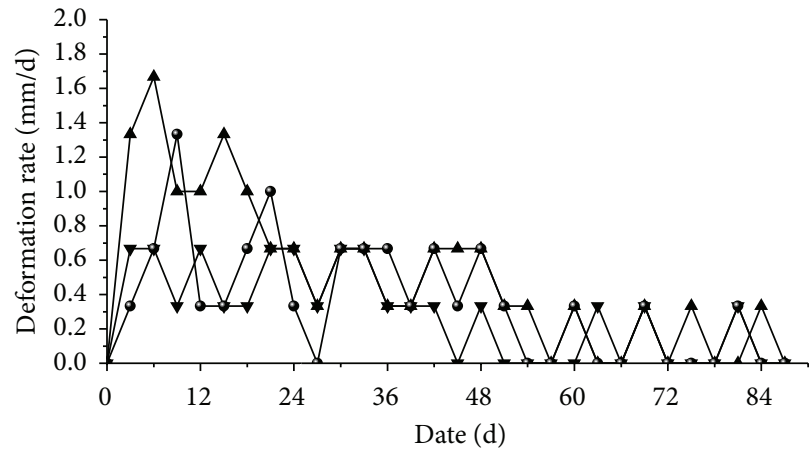

$\rightarrow$ Shrinkage rate of the two ribs

$\neg$ Settlement rate of roof

$\rightarrow$ Floor heave rate

(a) Roadway cross section 1

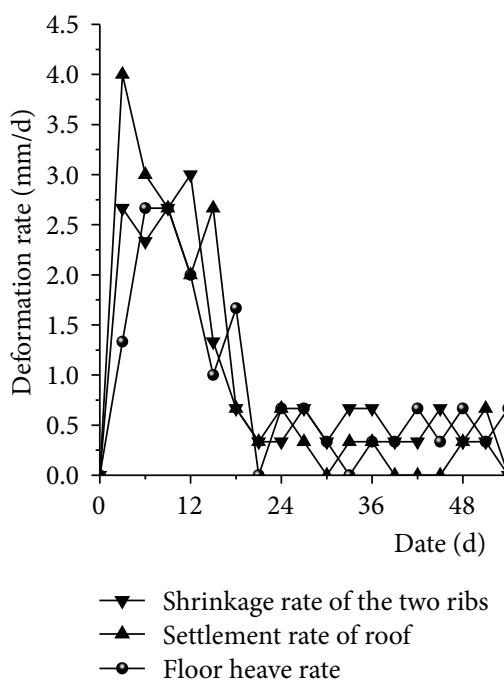

(c) Roadway cross section 3

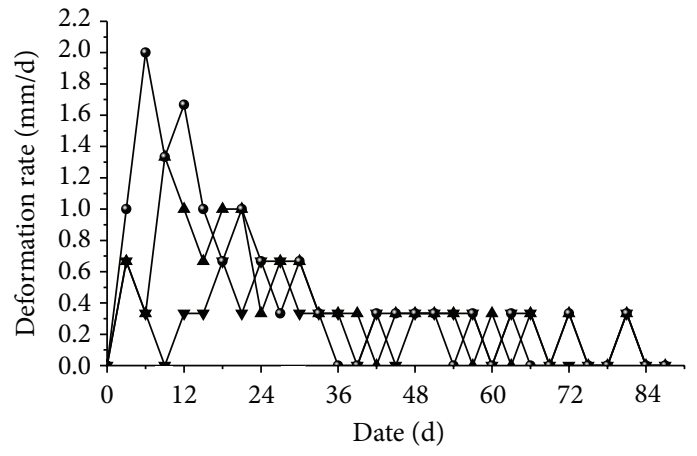

$\checkmark$ Shrinkage rate of the two ribs

$\rightarrow$ Settlement rate of roof

$\rightarrow$ Floor heave rate

(b) Roadway cross section 2

FIGURE 14: The rate of deformation of the roadway with the new support design.

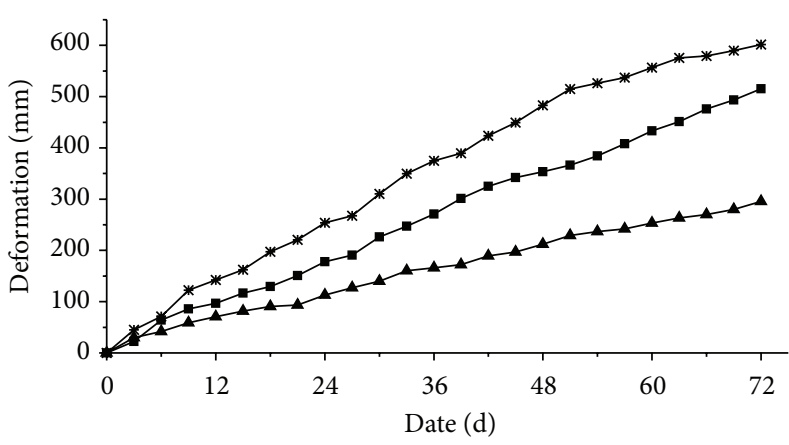

* Shrinkage of the two ribs

$\_$Settlement of roof

$\rightarrow$ Floor heave

(a) Roadway cross section 4

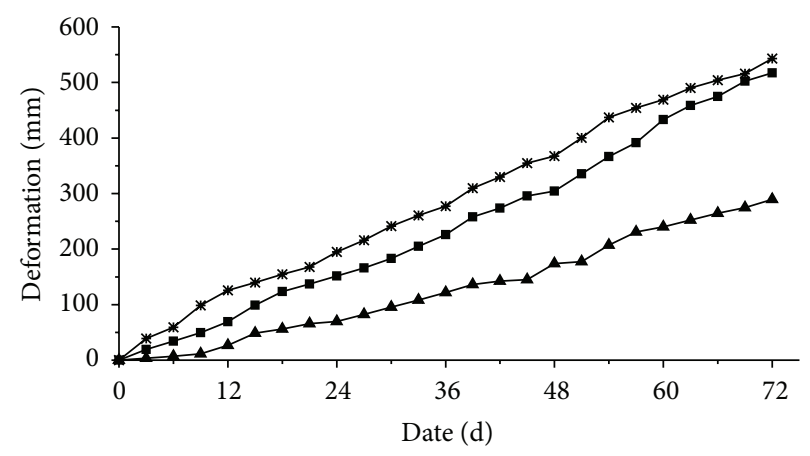

* Shrinkage of the two ribs

$\_$Settlement of roof

$\rightarrow$ Floor heave

(b) Roadway cross section 5

FIGURE 15: The cumulative deformation of the roadway with the old support design. 


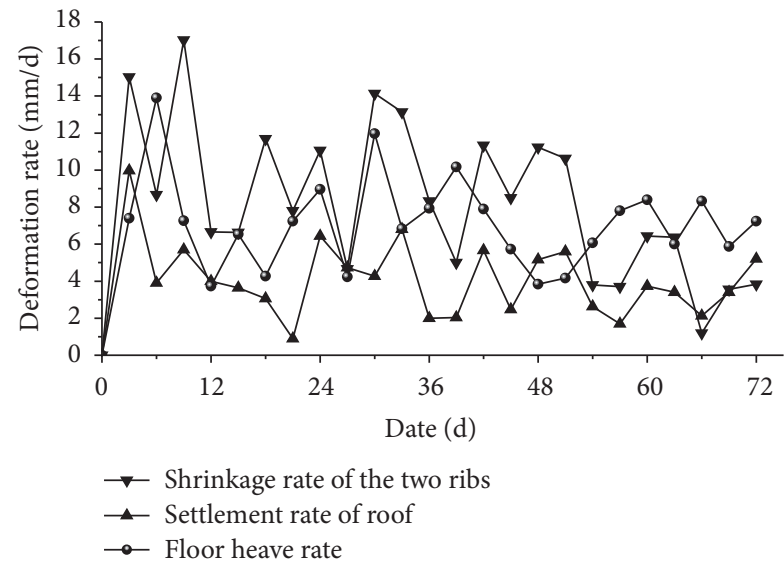

(a) Roadway cross section 4

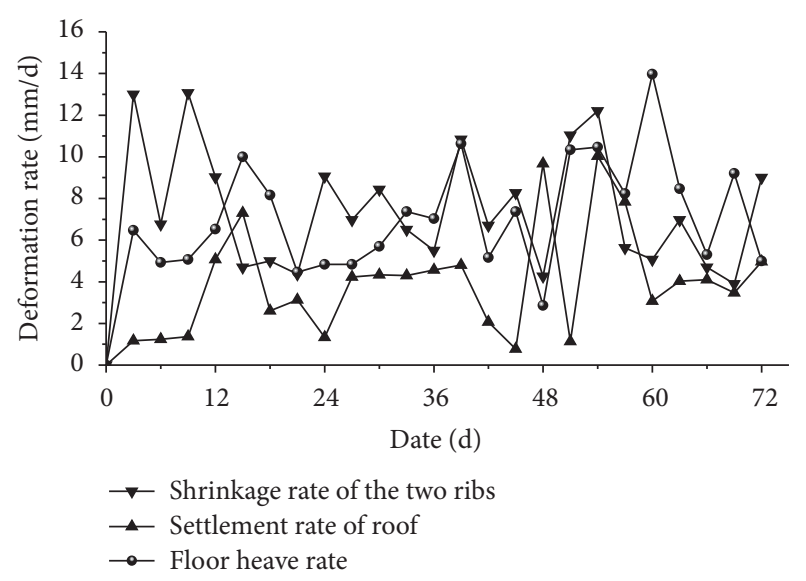

(b) Roadway cross section 5

FIGURE 16: The rate of deformation of the roadway with the old support design.

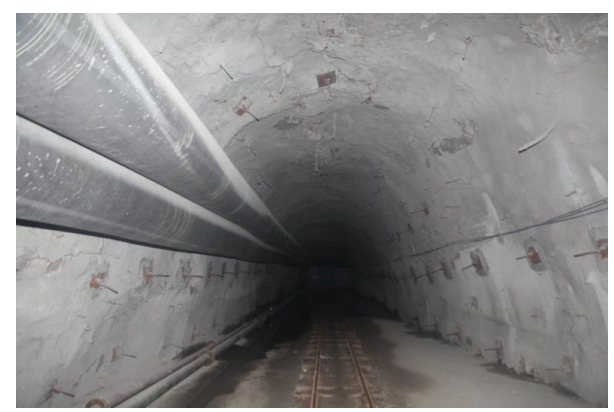

FIGURE 17: The roadway with new supporting design.

51204159), and Doctoral Fund of Ministry of Education of China (20130095110018). The authors thank the anonymous referees for their careful reading of this paper and valuable suggestions.

\section{References}

[1] B. Shen, "Coal mine roadway stability in soft rock: a case study," Rock Mechanics and Rock Engineering, vol. 47, no. 6, pp. 22252238, 2013.

[2] M. C. He, H. H. Jing, and X. M. Sun, Soft Rock Engineering Mechanics, Science Press, Beijing, China, 2002.

[3] Y. L. Lu, L. G. Wang, F. Yang, Y. Li, and H. Chen, "Post-peak strain softening mechanical properties of weak rock," Chinese Journal of Rock Mechanics and Engineering, vol. 29, no. 3, pp. 640-648, 2010.

[4] M. C. He, G. F. Li, J. Wang, and J. Cai, "Study on supporting design for large area serious roof caving of deep soft rock roadway in Xing'an coal mine," Chinese Journal of Rock Mechanics and Engineering, vol. 26, no. 5, pp. 959-964, 2007.

[5] Y. P. Wu, C. Wang, M. P. Li, Y. F. Zeng, and C. H. Huang, "Mechanism of roof-floor shearing deformation and breakage in coalmine of soft rock roadway," Journal of Xian University of Science and Technology, vol. 27, no. 4, pp. 539-543, 2007.

[6] C. Li, Z. L. Wang, and T. Liu, "Principle and practice of coupling support of double yielding shell of soft rock roadway under high stress," International Journal of Mining Science and Technology, vol. 24, no. 4, pp. 513-518, 2014.

[7] B. Meng, H.-W. Jing, K.-F. Chen, H.-J. Su, S.-Q. Yang, and Y.$\mathrm{H}$. Li, "Shear and slip failure mechanism and control of tunnels with weak surrounding rock," Chinese Journal of Geotechnical Engineering, vol. 34, no. 12, pp. 2255-2262, 2012.

[8] H. Salari-Rad, M. Mohitazar, and M. R. Dizadji, "Distinct element simulation of ultimate bearing capacity in jointed rock foundations," Arabian Journal of Geosciences, vol. 6, no. 11, pp. 4427-4434, 2013.

[9] R. Seedsman, "The stress and failure paths followed by coal mine roofs during longwall extraction and implications to tailgate support," in Proceedings of the 20th International Conference on Ground Control in Mining, pp. 42-49, Morgantown, WVa, USA, 2001.

[10] L. Yuan, J.-H. Xue, Q.-S. Liu, and B. Liu, "Surrounding rock stability control theory and support technique in deep rock roadway for coal mine," Journal of the China Coal Society, vol. 36, no. 4, pp. 535-543, 2011.

[11] L. Wu, C. Cui, N. Geng, and J. Wang, "Remote sensing rock mechanics (RSRM) and associated experimental studies," International Journal of Rock Mechanics and Mining Sciences, vol. 37, no. 6, pp. 879-888, 2000.

[12] W. P. Huang, Y. F. Gao, and J. Wang, "Deep rock tunnel's long large deformation mechanism and control technology under disturbance effects," Journal of China Coal Society, vol. 39, no. 5, pp. 822-828, 2014.

[13] H. P. Kang, J. Lin, and Y. Z. Wu, "Development of high pretensioned and intensive supporting system and its application in coal mine roadways," Procedia Earth and Planetary Science, vol. 1, pp. 479-485, 2009.

[14] Y.-Y. Jiao, L. Song, X.-Z. Wang, and A. Coffi Adoko, "Improvement of the U-shaped steel sets for supporting the roadways in loose thick coal seam," International Journal of Rock Mechanics and Mining Sciences, vol. 60, pp. 19-25, 2013.

[15] Y. L. Lu, L. G. Wang, and B. Zhang, "An experimental study of a yielding support for roadways constructed in deep broken soft rock under high stress," Mining Science and Technology, vol. 21, no. 6, pp. 839-844, 2011.

[16] C. Wang, Y. Wang, and S. Lu, "Deformational behaviour of roadways in soft rocks in underground coal mines and 
principles for stability control," International Journal of Rock Mechanics and Mining Sciences, vol. 37, no. 6, pp. 937-946, 2000.

[17] L.-G. Wang, M.-Y. Li, and X.-Z. Wang, "Study of mechanisms and technology for bolting and grouting in special soft rock roadways under high stress," Chinese Journal of Rock Mechanics and Engineering, vol. 24, no. 16, pp. 2889-2893, 2005.

[18] L.-G. Wang, H.-L. Li, and J. Zhang, "Numerical simulation of creep characteristics of soft roadway with bolt-grouting support," Journal of Central South University of Technology (English Edition), vol. 15, no. 1, supplement, pp. 391-396, 2008.

[19] H. Lisa, G. Gunnar, F. Åsa, and N. Tommy, "A statistical grouting decision method based on water pressure tests for the tunnel construction stage-a case study," Tunnelling and Underground Space Technology, vol. 33, pp. 54-62, 2013.

[20] S. Nadimi and K. Shahriar, "Experimental creep tests and prediction of long-term creep behavior of grouting material," Arabian Journal of Geosciences, vol. 7, no. 8, pp. 3251-3257, 2014.

[21] W. P. Huang, Y. F. Gao, and J. Wang, "Deep rock tunnel's long large deformation mechanism and control technology under disturbance effects," Journal of China Coal Society, vol. 39, no. 5, pp. 822-828, 2014.

[22] X. M. Sun, D. Wang, C. Wang, X. Liu, B. Zhang, and Z. Liu, "Tensile properties and application of constant resistance and large deformation bolts," Chinese Journal of Rock Mechanics and Engineering, vol. 33, no. 9, pp. 1765-1771, 2014.

[23] S. R. Torabi, H. Shirazi, H. Hajali, and M. Monjezi, "Study of the influence of geotechnical parameters on the TBM performance in Tehran-Shomal highway project using ANN and SPSS," Arabian Journal of Geosciences, vol. 6, no. 4, pp. 1215-1227, 2013.

[24] W. J. Wang, G. Peng, and J. Huang, "Research on high-strength coupling support technology of high stress extremely soft rock roadway," Journal of the China Coal Society, vol. 36, no. 2, pp. 223-228, 2011.

[25] X. Huang, Q.-S. Liu, and Z. Qiao, "Research on large deformation mechanism and control method of deep soft roadway in Zhuji coal mine," Rock and Soil Mechanics, vol. 33, no. 3, pp. 828-834, 2012.

[26] N. M. Esfahani and O. Asghari, "Fault detection in 3D by sequential Gaussian simulation of Rock Quality Designation (RQD)," Arabian Journal of Geosciences, vol. 6, no. 10, pp. 37373747, 2013.

[27] M. R. Shen and J. F. Chen, Rock Mechanics, Tongji University Press, Shanghai, China, 2006.

[28] Q. S. Li, F. L. Bo, X. Y. Ding et al., "Deformation characteristics of soft rock roadway in deep mines and supporting control technology," Journal of Shandong University of Science and Technology (Natural Science), vol. 29, no. 4, pp. 8-14, 2010.

[29] S. C. Li, H. P. Wang, Q. H. Qian et al., "In-situ monitoring research on zonal disintegration of surrounding rock mass in deep mine roadways," Chinese Journal of Rock Mechanics and Engineering, vol. 27, no. 8, pp. 1545-1553, 2008.

[30] Y.-L. Lu, L.-G. Wang, B. Zhang, and Y.-J. Li, "Optimization of bolt-grouting time for soft rock roadway," Rock and Soil Mechanics, vol. 33, no. 5, pp. 1395-1401, 2012. 

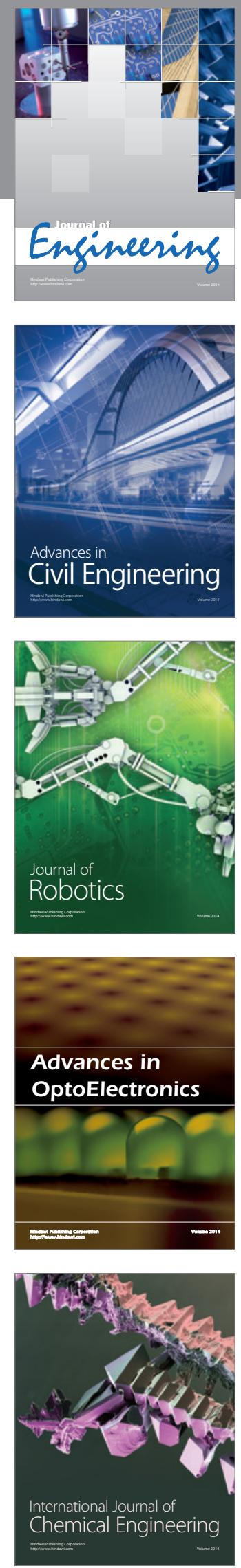

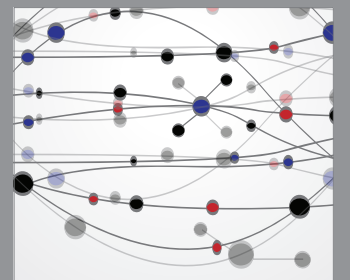

The Scientific World Journal
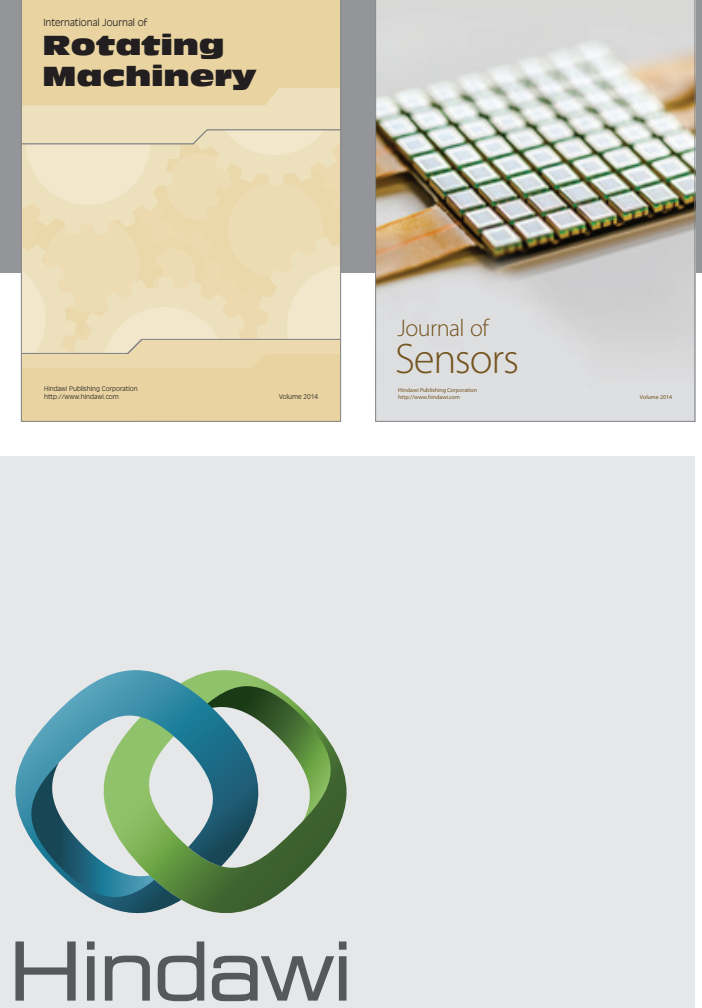

Submit your manuscripts at http://www.hindawi.com
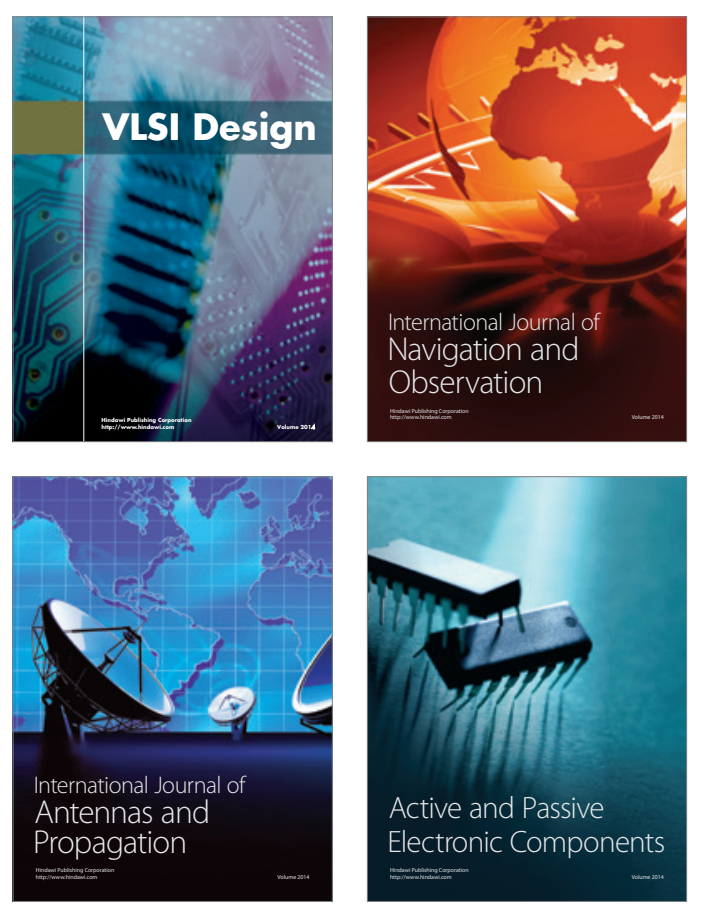
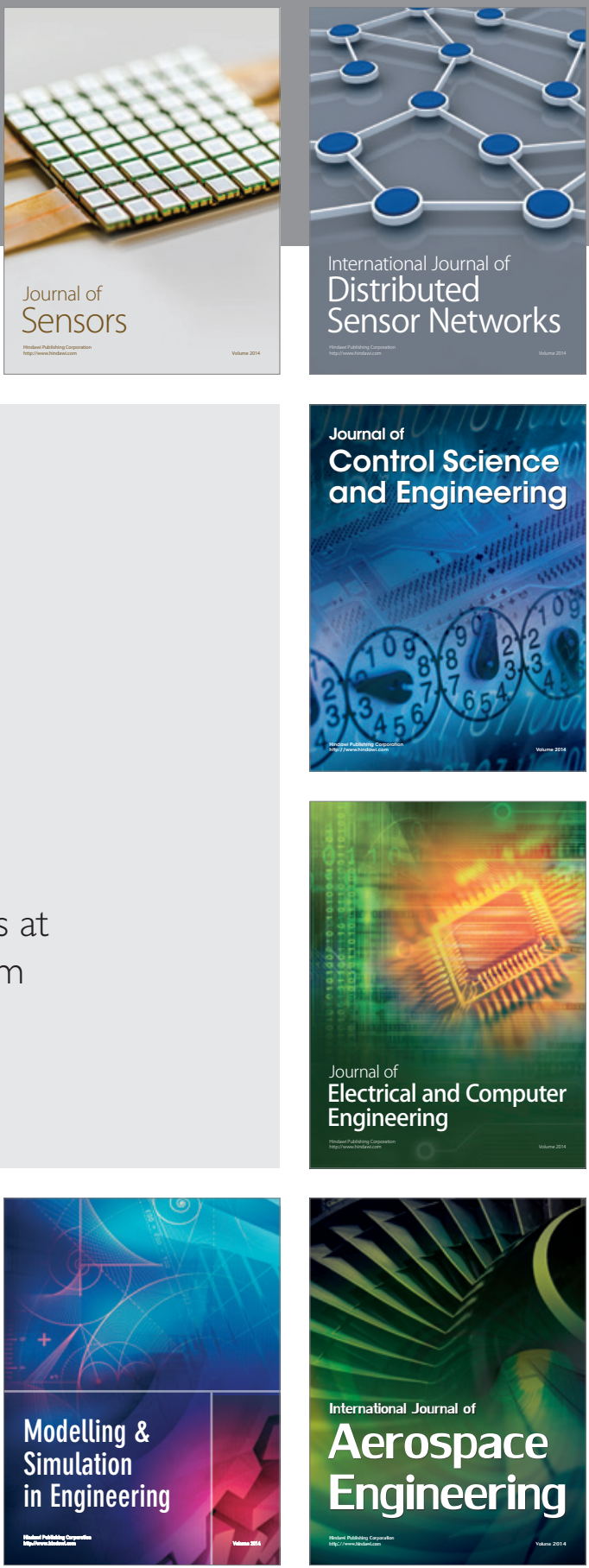

Journal of

Control Science

and Engineering
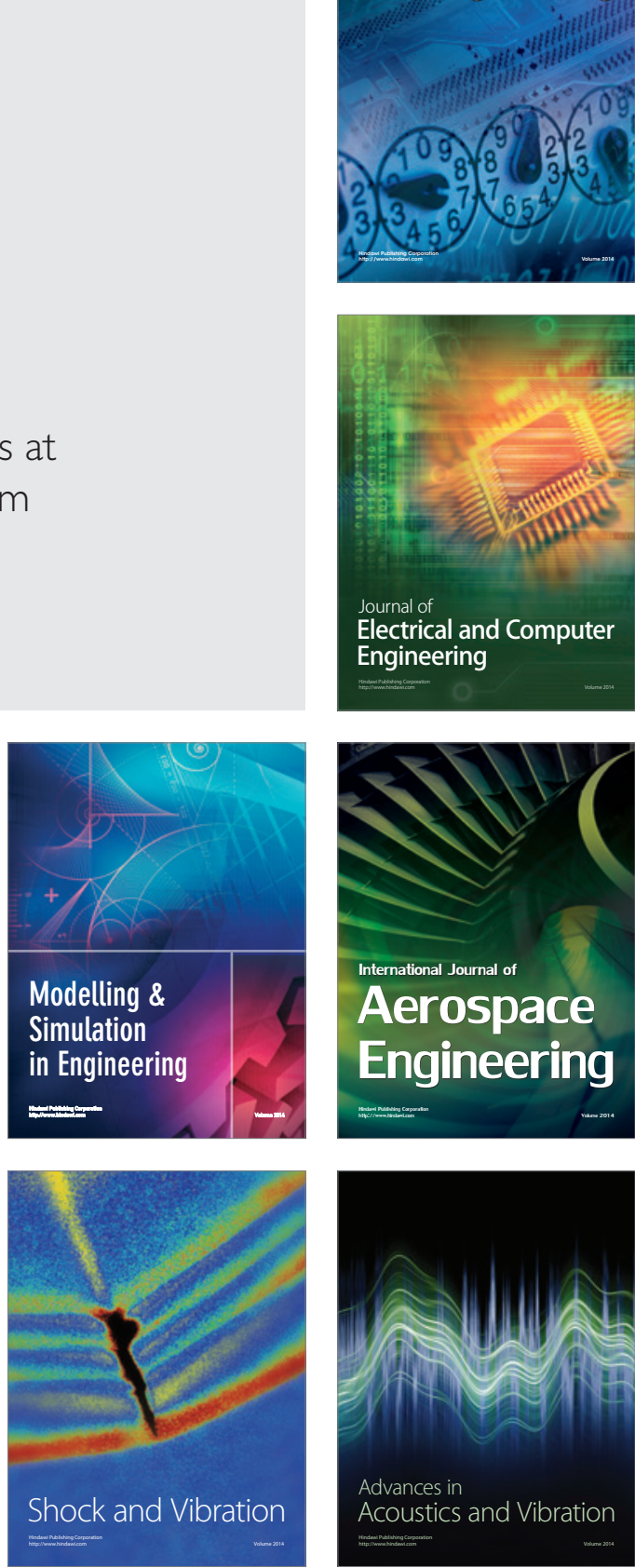